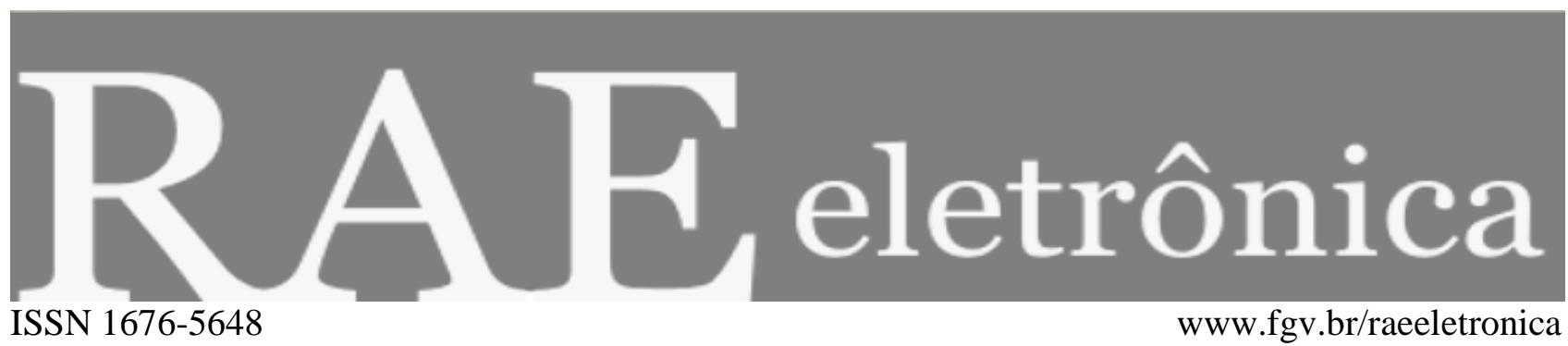

\title{
ARTIGOS
}

\section{EXECUTIVAS: CARREIRA, MATERNIDADE, AMORES E PRECONCEITOS*}

FEMALE EXECUTIVES: CAREER, MOTHERHOOD, LOVE AND PREJUDICE

EJECUTIVAS: CARRERA, MATERNIDAD, AMORES Y PREJUICIOS

\author{
Antonio Moreira de Carvalho Neto \\ Professor do Programa de Pós Graduação em Administração, Pontifícia Universidade Católica de \\ Minas Gerais - Belo Horizonte - MG, Brasil \\ carvalhoneto@pucminas.br
}

\section{Betania Tanure}

Professora do Programa de Pós Graduação em Administração, Pontifícia Universidade Católica de Minas Gerais - Belo Horizonte - MG, Brasil

betaniatanure@pucminas.br

\section{Juliana Andrade}

Doutoranda pelo CEPEAD da Universidade Federal de Minas Gerais - Belo Horizonte - MG, Brasil juolive@terra.com.br

Recebido em 16.04.2008. Aprovado em 04.05.2010. Disponibilizado em 08.06.2010

Avaliado pelo sistema double blind review

Editor Científico: Janette Brunstein

RAE-eletrônica, v. 9, n. 1, Art. 3, jan./jun. 2010.

http://www.rae.com.br/eletronica/index.cfm?FuseAction=Artigo \&ID=5275\&Secao=ARTIGOS\&Volume=9\&Numero=1 $\&$ Ano $=2010$

CCopyright 2010 FGV-EAESP/RAE-eletrônica. Todos os direitos reservados. Permitida a citação parcial, desde que identificada a fonte. Proibida a reprodução total. Em caso de dúvidas, consulte a Redação: raeredacao@fgv.br; 55 (11) 3799-7898.

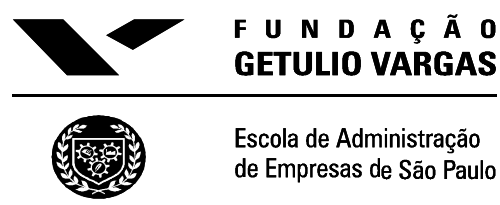




\title{
RESUMO
}

Este artigo analisa a percepção das mulheres executivas que chegaram ao topo da hierarquia organizacional das grandes empresas no Brasil sobre os desafios à sua carreira. O referencial teórico explora os determinantes de sucesso na carreira: estrutura, o capital humano, a família, socioeconômicos, investimentos no trabalho e expectativas de recompensa. $\mathrm{O}$ artigo baseia-se em um método misto quantitativo-qualitativo. A pesquisa quantitativa contou com 965 respondentes, sendo 222 mulheres, numa amostra de 344 dentre as maiores empresas do país. A pesquisa qualitativa contou com 263 respondentes, dentre os quais 48 mulheres, em 10 grandes empresas de vários setores. Os resultados mostram que os obstáculos às altas exigências da carreira são colossais: preconceitos arraigados; pressão do relógio biológico; sobrecarga com os cuidados com os filhos versus jornada de trabalho muito extensa; dificuldades com o parceiro amoroso. Apesar de tudo, ainda que estejam insatisfeitas com o desequilíbrio entre seu tempo de trabalho e o de não trabalho, as mulheres executivas continuam apostando na carreira.

PALAVRAS-CHAVE Mulheres executivas, carreira e família, carreira e maternidade, carreira e parceiro amoroso, preconceito.

\begin{abstract}
This article analyses the views of female Brazilian executives who have reached the top of the organizational hierarchy on the challenges they face in their careers. The theoretical framework discusses career success determinants: structure, human capital, family, socioeconomic factors, investment in career and reward expectations. The article is based on a quantitative-qualitative methodological approach. The quantitative research collected data from 965 people, of whom 222 were female managers, from 344 of Brazil's largest corporations. The qualitative research is based on 263 interviews, of which 48 are with women, in 10 large corporations from several economic sectors. Results show that there are enormous obstacles to female careers: deep-rooted prejudice; biological pressure to have children; overload, with concerns relating to their children versus over-long working hours; difficult relations with their partners. Despite everything, even though they are unsatisfied with the lack of balance between working and non-working times, female executives do not intend giving up their careers.
\end{abstract}

KEYWORDS Female executives, career and family, career and motherhood, career and the partner; prejudice.

\section{RESUMEN}

Este artículo analiza la percepción de las mujeres ejecutivas que llegaron a la cumbre de la jerarquía organizacional de las grandes empresas en Brasil, sobre los desafíos de su carrera. El referencial teórico explora los determinantes de éxito en la carrera: estructura, capital humano, familia, socioeconómicos, inversión en el trabajo y expectativa de recompensa. El artículo se basa en un método mixto cuantitativo-cualitativo. La encuesta cuantitativa contó con 965 encuestados, de los cuales 222 eran mujeres, en una muestra de 344 empresas entre las mayores del país. La encuesta cualitativa contó con 263 encuestados, entre los cuales 48 eran mujeres, en 10 grandes empresas de varios sectores. Los resultados muestran que los obstáculos en dirección a las altas exigencias de la carrera son colosales: prejuicios arraigados; presión del reloj biológico; sobrecarga por el cuidado de los hijos versus jornada de trabajo muy extensa; dificultades con su pareja. A pesar de todo, aunque estén insatisfechas con el desequilibrio entre el tiempo de trabajo y el de no trabajo, las mujeres ejecutivas continúan apostando en la carrera.

PALABRAS CLAVE Mujeres ejecutivas, carrera y familia, carrera y maternidad, carrera y pareja, prejuicios. 


\section{INTRODUÇÃO}

O objetivo deste artigo é investigar a relação das mulheres executivas que chegaram ao topo da hierarquia de empresas que atuam no Brasil com a carreira, a maternidade, a dedicação à família e ao parceiro amoroso.

Na maioria dos países ocidentais, observa-se um aumento contínuo da participação da mulher no mercado de trabalho, embora permaneçam desigualdades de rendimento em relação aos homens. (VAN VIANEN; FISHER, 2002; GRYBAITE, 2006). Fruto da luta feminista pela igualdade entre os sexos, esse aumento caminha pari passu com a maior necessidade econômica de contribuir no orçamento familiar, com o significativo aumento do nível de escolaridade das mulheres e com a diminuição de barreiras culturais ao ingresso da mulher no mercado de trabalho. Entretanto, barreiras permanecem, e ainda são poucas as mulheres que chegam ao topo da hierarquia empresarial, encontrando muitos óbices nesse caminho, no Brasil e em países como os EUA e a Espanha, por exemplo. (BETIOL; TONELLI, 1991; VAN VIANEN; FISHER, 2002; CHINCHILLA; LEÓN, 2005; REINHOLD, 2005). No Brasil, enquanto as taxas de atividade masculina mantiveram patamares semelhantes, as das mulheres ampliaram-se significativamente (BRUSCHINI, 2000).

A pesquisa em que se baseia este artigo é rara na área de Administração, devido à sua abrangência e em relação à posição hierárquica que ocupam os executivos e as executivas entrevistadas nas maiores empresas que operam no Brasil (344 empresas). Ela contou com 965 executivos, homens e mulheres, presidentes, vice-presidentes/diretores e superintendentes, na parte quantitativa; e 263, dentre eles, na parte qualitativa. O caráter misto quantitativo-qualitativo também é raro na literatura de gestão, pois, para tal, é preciso que os dados sejam de uma amostra muito significativa dos dois métodos, o que foi possível neste trabalho. Realizada em dois anos, a pesquisa produziu uma vasta gama de dados sobre significativa amostra, dados esses que foram submetidos a rigoroso tratamento estatístico e analítico. A partir da percepção das executivas sobre os níveis de satisfação e estresse com sua vida profissional e fora do trabalho, investigou-se sua relação com a carreira, a maternidade, a dedicação à família e ao parceiro amoroso. Os preconceitos machistas no ambiente empresarial, que se constituem também em óbices à carreira, são igualmente tratados.

Além do acima exposto, em relação ao número da amostra, a pesquisa contribui para o conhecimento existente nas áreas de gestão de pessoas e também de estudos organizacionais, devido ao conjunto de aspectos supracitados. $\mathrm{O}$ fato de apresentar aqui a percepção das mulheres executivas que alcançaram o almejado Olimpo empresarial, falando de suas mazelas e seu sofrimento, é por si só uma 
contribuição significativa que renova o fôlego de estudos relativos ao sofrimento no trabalho, geralmente afeitos aos trabalhadores e gerentes de nível operacional.

A questão da mulher executiva, inclusive sua vida amorosa e sua relação com o trabalho, tratada da forma descrita acima, é pouco discutida na literatura no Brasil. Tonelli (2001) faz uma boa discussão teórica, sem apoio de dados empíricos. Betiol e Tonelli (1991) partem de uma base de dados menor do que aquela que aqui se apresenta para produzir análise qualitativa. Já autores como Cappelle (2006) dão sua importante contribuição sem focar em executivas, utilizando base qualitativa. Autores como Bruschini (2000), Wajnman e Rios-Neto (2000), da área de demografia, sempre partem de dados quantitativos agregados, e não especificamente do universo das executivas. Quando tratam de executivas, não abordam aspectos como o da vida amorosa e a relação com a maternidade. Autores norte-americanos, como, por exemplo, Martins, Eddleston e Veiga (2002), abordam vários desses aspectos. No entanto, utilizam pesquisas quantitativas e praticamente não utilizam pesquisa qualitativa.

O referencial teórico explora os tremendos desafios que essas mulheres seguem enfrentando.

\section{A MULHER EXECUTIVA: CARREIRA, MATERNIDADE, AMORES E PRECONCEITOS}

Um elemento fortemente diferenciador da relação entre a mulher e o homem na organização é a sexualidade e o temor do seu uso indevido. Desse temor derivam pelo menos dois preconceitos: primeiro, que a mulher atingiu o topo porque usou de sua sexualidade; segundo, que ela se comporta “como homem". Reflexo desses preconceitos, a mulher tem que lidar com uma contradição: para ser respeitada, tem que pensar, agir e trabalhar "como homem", mas para ser amada tem que ser feminina, delicada, atenciosa, enfim, possuir predicados que desde a Antiguidade são atribuídos à mulher. (BETIOL; TONELLI, 1991). A mulher executiva sofre ainda mais pressões, pois teve que derrotar vários homens, que também disputavam o cargo que ela conquistou.

Afinal, a cultura corporativa ainda é masculina (AYCAN, 2004; REINHOLD, 2005). A mulher executiva teve que se adaptar às exigências e ao ambiente que as organizações lhe propiciam; vai construindo sua identidade, segundo a cultura da empresa na qual está inserida. Para galgar postos mais altos na hierarquia organizacional escapando da definição estereotipada de delicada e frágil, dentre outros "atributos", acaba utilizando predicados masculinos em seu favor (BELLE, 1993).

Chênevert e Tremblay (2002) apontam algumas diferenças que pretendem explicar os determinantes de menor sucesso na carreira feminina, comparando-a com a masculina. Esses 
determinantes são o capital humano, a família, os aspectos socioeconômicos, os investimentos no trabalho e as expectativas de recompensa, além dos determinantes estruturais (por exemplo, existem setores de atividade ainda muito masculinos, como a indústria).

Os determinantes do capital humano indicam que os indivíduos que investem mais em educação e treinamento são os que obtêm mais opções na carreira. Os homens, historicamente, puderam investir mais em sua carreira profissional do que as mulheres. Além disso, os homens tendem a excluir as mulheres das redes informais de relacionamento entre executivos, importante canal de ascensão e permanência na carreira (KIRCHMEYER, 1998; AYCAN, 2004; REINHOLD, 2005).

Sobre os determinantes da família, estudos apontam que os homens são os mais beneficiados com o casamento, pois a mulher casada que não participa ativamente do mercado de trabalho é considerada como "recurso adicional" ao marido, para que ele invista mais na carreira (CHÊNEVERT e TREMBLAY, 2002). O contrário, entretanto, raramente acontece. Mulheres casadas com filhos crianças tendem a investir mais na família e menos na carreira (NEUMARK; MCLENNAN, 1994; KIRCHMEYER, 1998; REINHOLD, 2005).

As diferenças comportamentais diferem de acordo com a cultura de cada país (HOFSTEDE, 2001; TANURE, 2005). Em culturas mais masculinas, a expectativa do papel a ser desempenhado pelos homens está mais ligada às atividades externas ao lar; espera-se que os homens sejam mais duros, firmes e competitivos. Esse papel que é esperado do homem em culturas mais masculinas difere em muito da expectativa do papel a ser desempenhado pelas mulheres (VAN VIANEN; FISHER, 2002).

Em culturas mais femininas, as expectativas dos papéis desempenhados pelo homem e pela mulher não têm diferenças tão significativas. Tanto um quanto o outro pode estar ligado às atividades externas, à carreira, ao sucesso e ao dinheiro, como também pode ser responsável pela harmonia das relações e qualidade de vida. Isso explicaria porque, em culturas mais femininas, como nos países escandinavos, a mulher já avançou mais em relação à igualdade e os homens já tendem a considerar que é também sua função cuidar do dia a dia dos filhos, o que abre mais espaço para a mulher se dedicar à carreira. No entanto, o caso escandinavo é raro, mesmo entre os países mais desenvolvidos (HEWLETT, 2002).

Em países de tradição cultural machista como o Brasil, o avanço da participação da mulher no mercado de trabalho ainda não foi capaz de se traduzir em significativa divisão de responsabilidades em relação às crianças. Pesquisas sugerem que as mulheres, na média, enfrentam mais estresse no desempenho do seu papel familiar do que os homens, e que, no equilíbrio entre os papéis no trabalho e 
na família, as mulheres tendem a trocar as responsabilidades familiares pelas responsabilidades do trabalho (MARTINS; EDDLESTON; VEIGA, 2002).

Certamente, a cultura não é o único fenômeno que explica as diferenças, e muito menos isoladamente. As diferenças são também fruto de disputas sociais, inclusive os conflitos para definir os lugares por eles/as ocupados na sociedade. A estrutura da economia de cada país também tem influência: as mulheres foram historicamente forçadas a integrar o exército de reserva de mão de obra.

No Brasil, dada a grande disponibilidade de mão de obra barata, as mulheres executivas podem "terceirizar" algumas funções, contando com ajuda substancial de empregadas domésticas, babás e outras profissionais, que assumem tarefas que antes eram desenvolvidas pela mãe no cuidado com os filhos. Ainda assim, a orientação quanto a valores e definição de limites não é facilmente transferida, o que representa uma carga adicional para a mulher executiva.

A menor mobilidade da mulher, devido ao compromisso maior com a criação dos filhos, também pode ser outro fator incluído no determinante família que dificulta seu avanço na hierarquia organizacional, a qual exige constantes viagens. Geralmente a mulher não muda a moradia do marido e dos filhos em função da demanda da empresa, quando o contrário quase sempre ocorre com os homens.

Um fenômeno cada vez mais frequente numa economia que está se globalizando, a expatriação, leva muitas pessoas a viverem e trabalharem fora da região geográfica onde moram. (GLANZ, WILLIAMS e HOEKSEMA, 2001). Algumas razões são citadas na literatura para explicar a ausência de mulheres executivas como expatriadas (FISCHLMAYR, 2002), dentre elas a que algumas culturas não aceitam mulheres como força de trabalho. Outra razão refere-se aos estereótipos relativos ao gênero, discutidos anteriormente, que podem se transformar em discriminação por parte de colegas e chefes homens. O homem que acompanha a mulher expatriada se sente mais entediado e/ou perdido do que a mulher que acompanha o marido expatriado. As empresas tendem a ter dificuldade em expatriar uma executiva casada, antecipando todos esses problemas com o marido (TAYLOR; NAPIER; MAYRHOFER, 2002).

No Brasil, há uma mudança no perfil etário da População Economicamente Ativa feminina, mostrando aumento do trabalho das esposas, sugerindo que as responsabilidades financeiras familiares estão sendo mais divididas (BRUSCHINI, 2000). Num movimento que se iniciou com uma necessidade de complementação de renda, além da elevação da escolaridade, diminuição do número de filhos, mudança da identidade feminina e nas relações familiares, as mulheres, casadas ou não, procuram disputar mais o seu lugar no mercado de trabalho. 
Sobre os determinantes relativos aos investimentos no trabalho e expectativas de recompensa, estudos na área de demografia indicam que os fatores que influenciam a disposição de homens e mulheres para o trabalho são distintos. O padrão de atividade dos homens é mais homogêneo, entre 20 e 49 anos. Já o ciclo de vida ativa profissional da mulher apresenta diversos perfis etários típicos, observados em países diferentes, refletindo questões distintas entre a atividade feminina e o ciclo de casamento e formação da família (WAJNMAN; RIOS-NETO, 2000).

Os valores culturais incutidos na mulher influenciam seu nível de investimento no trabalho e também sua percepção de fracasso (CHÊNEVERT; TREMBLAY, 2002). Betiol e Tonelli (1991) chamam a atenção para a possibilidade de o fracasso profissional feminino ter um peso menor do que o masculino. Esse fracasso está ligado ao medo de deixar de cumprir um papel extremamente valorizado pela cultura brasileira, que é o de mãe e esposa.

Os determinantes estruturais apontados por Chênevert e Tremblay (2002) podem explicar o baixo percentual de mulheres que atingem o topo da hierarquia organizacional. Alguns trabalhos ainda são referidos como masculinos, e a presença feminina não é bem aceita. Estudos mostram que alguns subsetores de atividade, notadamente na indústria, ainda são restritivos à presença feminina.

Além de todos esses desafios para a carreira da mulher executiva, ainda há questões específicas quanto à sua relação com o parceiro amoroso e a maternidade que influenciam negativamente sua vida profissional. Pesquisa nos EUA, realizada com o objetivo de explorar a vida profissional e privada de mulheres bem remuneradas e com elevado nível de instrução, sugere que, quanto mais bem-sucedido o homem, maior é a probabilidade de que ele se case e tenha filhos. Com as mulheres bem-sucedidas ocorre o inverso. Aquelas que desejam ser mães e executivas enfrentam maiores dificuldades para encontrar um parceiro amoroso (HEWLETT, 2002).

Outro fator que pressiona a mulher executiva é a sobreposição das demandas profissionais e da maternidade. Os primeiros anos de ascensão na carreira profissional se sobrepõem aos anos mais apropriados biologicamente para a maternidade. Após os 35 anos, a fertilidade da mulher diminui drasticamente (VIRTALA e outros, 2006). Portanto, a mulher nessa faixa que ainda não teve filho, já tendo alcançado sucesso na carreira, fica extremamente pressionada exatamente quando a demanda da empresa aumenta em relação à sua dedicação ao trabalho.

Consequência do quadro de "terceirização" das tarefas domésticas discutido mais acima, como é consenso entre vários autores, como Freitas (1998), o trabalho demanda atualmente fortes exigências. Horas excessivas de trabalho promovem constante ausência da mulher de sua casa. Além disso, mesmo 
estando em casa, tanto o homem quanto a mulher sofrem da "ausência psicológica" apontada por Evans e Bartolomé (1980), que é o sentimento de estar presente, porém não disponível psicologicamente.

Essa ausência tende a ser muito maior quando as empresas passaram a exigir uma postura de maior proatividade e antecipação de eventuais problemas, além de terem aumentado bastante a cobrança de resultados. Esse quadro é potencializado pelo uso de e-mails, telefones celulares e laptops em casa, o que dificulta a disponibilidade para a família. É o paradoxo do estar presente estando ausente. Sem forças para lutar contra esse panorama, a mulher pode se sentir culpada.

\section{CONSIDERAÇÕES METODOLÓGICAS}

A pesquisa adotada neste estudo é de caráter descritivo. Recomenda-se a pesquisa descritiva quando já se tem acúmulo suficiente sobre determinada temática (GIL, 1999), como é o caso da mulher no mercado de trabalho em geral, que serve de apoio à discussão da mulher executiva no mercado de trabalho.

Este artigo baseia-se em abrangente pesquisa realizada com executivos homens e mulheres. A estratégia de pesquisa recaiu sobre o método misto qualitativo-quantitativo, como explica Creswell (2003), onde um complementa o outro. A utilização do método misto pode neutralizar ou cancelar vieses dos métodos utilizados separadamente. Em termos de estratégia, utilizamos procedimentos sequenciais, que, para Creswell (2003), consistem numa tentativa de elaborar ou expandir os resultados de um método para outro. Em nossa pesquisa, começamos com a parte quantitativa, aplicando um questionário fechado. Depois, prosseguimos com o método qualitativo, com a realização de entrevistas individuais e grupos de foco. Essa fase envolveu uma exploração mais detalhada, via roteiro semiestruturado, dos tópicos mapeados previamente na parte quantitativa e a expansão de outras questões que se mostraram relevantes ao longo do trabalho de campo.

A amostra para selecionar as 344 grandes empresas participantes da parte quantitativa foi definida de forma aleatória, utilizando-se a base das "500 maiores e melhores" empresas do anuário da revista Exame, entre indústria $(47,5 \%)$ e serviços $(50,4 \%)$. Os dados foram coletados num período de dois anos (2005-2006).

Na parte quantitativa, obtiveram-se 965 respondentes a um questionário fechado, homens e mulheres executivos, presidentes, vice-presidentes, diretores e executivos de terceiro nível (imediatamente abaixo dos vice-presidentes e diretores). O questionário é bastante amplo, organizado 
em seis grandes tópicos, totalizando 30 questões, com suas respectivas subdivisões. Nessa parte quantitativa, obtivemos respostas de 222 mulheres executivas ao questionário fechado.

$\mathrm{Na}$ parte qualitativa, foram entrevistados 263 executivos, homens e mulheres de 10 grandes empresas nas mesmas posições hierárquicas da pesquisa quantitativa descrita anteriormente, por meio de roteiros semiestruturados, sendo 96 individualmente e 167 por meio de 14 grupos de foco. As 10 grandes empresas são da indústria de alimentos, automotiva e petroquímica; telecomunicações; bancos; comunicação. Nessa parte qualitativa, foram entrevistadas 48 mulheres executivas, selecionadas por acessibilidade, respeitando critérios como idade, estado civil, número de filhos e cargo, buscando representar um perfil diversificado.

Os relatos discutidos neste artigo são representativos tanto das entrevistas com as executivas quanto dos grupos focais nos quais elas estavam sempre presentes. Na análise dos dados a seguir, sempre que nos referirmos aos entrevistados, estamos fazendo alusão a $70 \%$ da percepção predominante na amostra entrevistada. Nossa análise para este artigo utilizou especialmente os depoimentos das mulheres, fazendo contraponto com a opinião dos homens.

Para as entrevistas individuais, que tiveram duração média de uma hora, foram escolhidos os principais dirigentes, homens e mulheres, das 10 empresas: o presidente, os vice-presidentes e diretores. Como cada uma das grandes empresas tem uma média de 10 pessoas nesse topo da pirâmide hierárquica, foi entrevistado praticamente todo esse universo, o que se constitui em raro feito, considerando público de tão difícil acesso.

Para os grupos de foco, as empresas forneceram a lista dos executivos e executivas de terceiro escalão, abaixo de diretores e vice-presidentes. A equipe de pesquisadores escolheu de forma aleatória, de acordo com a maior diversidade possível em relação a critérios de sexo, idade, tempo de empresa, setor em que atua na empresa, de forma que houvesse metade de mulheres onde fosse possível.

Dado o extenso número de variáveis e o tamanho muito significativo da amostra quantitativa, utilizaram-se as seguintes ferramentas estatísticas:

- Teste Qui Quadrado: avalia a associação entre duas variáveis categóricas, onde pelo menos uma delas não é ordinal. Essa comparação é feita pela comparação de valores observados em cada categoria com os valores esperados (estimados), sendo que, uma vez que o valor p (ou "p-valor") desta estatística é menor ou igual a 0,05, diz-se existir uma associação estatisticamente significativa entre as variáveis.

- ANOVA (a um fator): usada para testar a igualdade de três ou mais médias ao mesmo tempo, provenientes de amostras independentes. ANOVA a um fator significa dizer que a característica - fator 
- que diferencia cada amostra é a mesma. ANOVA para comparar duas amostras de grupos distintos é equivalente ao teste $\mathrm{t}$ (TRIOLA, 1999). A comparação entre amostras é feita por meio de teste que avalia a variação entre as amostras; quanto maior essa variabilidade, maior a evidência contra a hipótese de igualdade das médias. Assim, quando o 'valor p desta estatística é menor que 0,05, afirmase que existe alguma diferença entre as médias avaliadas. No entanto, esse teste somente não aponta onde se encontra essa diferença. Para descobri-la, usou-se o método de comparações múltiplas (método de Duncan), que retorna quais grupos apresentaram diferença significativa em relação aos demais (comparadas duas a duas).

Construímos dois índices para avaliar a percepção do conjunto de executivos homens e mulheres sobre a satisfação e sobre sensações e atitudes em relação ao equilíbrio entre vida pessoal e demandas da carreira. Esses dois índices foram obtidos pela média dos indicadores, relativa à soma dos itens com respostas completas/valor máximo. Por meio de escala Likert de 1 a 7 , variando de "extremamente insatisfeita" até "extremamente satisfeita", avaliamos o que denominamos "Índice Global de Satisfação", composto por dois fatores que abarcaram um conjunto de 18 indicadores, como mostra a Tabela 1.

\section{Tabela 1 - Índice Global de Satisfação}

\begin{tabular}{|c|c|c|c|c|c|c|}
\hline & Ordem $^{(1)}$ & Item de Satisfação & $\begin{array}{c}\mathrm{N} \\
\text { válido } \\
\end{array}$ & Média & Mediana & $\begin{array}{l}\text { Desvio } \\
\text { padrão }\end{array}$ \\
\hline 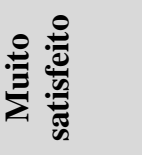 & 1 & Satisfação com a relação com os filhos & 764 & 5,6 & 6 & 1,2 \\
\hline \multirow{11}{*}{ } & 2 & Satisfação com a relação com o parceiro amoroso & 945 & 5,4 & 6 & 1,4 \\
\hline & 3 & $\begin{array}{l}\text { Satisfação com as relações estabelecidas com os } \\
\text { subordinados }\end{array}$ & 937 & 5,2 & 5 & 1 , \\
\hline & 4 & $\begin{array}{l}\text { Satisfação com a assistência médica oferecida } \\
\text { pela empresa }\end{array}$ & 945 & 5 , & 5 & 1,4 \\
\hline & 5 & Satisfação com a saúde & 965 & 4,9 & 5 & 1,2 \\
\hline & 5 & Satisfação com a relação com outros familiares & 960 & 4,9 & 5 & 1,2 \\
\hline & 5 & $\begin{array}{l}\text { Satisfação com as relações estabelecidas com o } \\
\text { superior }\end{array}$ & 950 & 4,9 & 5 & 1,3 \\
\hline & 5 & $\begin{array}{l}\text { Satisfação com as relações estabelecidas com os } \\
\text { pares }\end{array}$ & 951 & 4,9 & 5 & 1 , \\
\hline & 9 & $\begin{array}{l}\text { Satisfação com os demais benefícios que a } \\
\text { empresa oferece }\end{array}$ & 950 & 4,8 & 5 & 1,3 \\
\hline & 10 & Satisfação com o número de amigos que tem & 965 & 4,7 & 5 & 1,3 \\
\hline & 10 & $\begin{array}{l}\text { Satisfação com o nível de desafios colocados pela } \\
\text { empresa }\end{array}$ & 960 & 4,7 & 5 & 1,2 \\
\hline & 12 & $\begin{array}{l}\text { Satisfação com a factibilidade das metas } \\
\text { estabelecidas pela empresa }\end{array}$ & 952 & 4,5 & 5 & 1,2 \\
\hline
\end{tabular}


ARTIGO - EXECUTIVAS: CARREIRA, MATERNIDADE, AMORES E PRECONCEITOS

Antonio Moreira de Carvalho Neto, Betania Tanure e Juliana Andrade

\begin{tabular}{cclcccc} 
& 12 & Satisfação com a convivência com os amigos & 961 & 4,5 & 5 & 1,3 \\
\hline & 14 & $\begin{array}{l}\text { Satisfação com o nível de cobranças por } \\
\text { resultados na empresa }\end{array}$ & 959 & 4,4 & 5 & 1,2 \\
& 14 & $\begin{array}{l}\text { Satisfação com a remuneração fixa recebida pelo } \\
\text { trabalho }\end{array}$ & 961 & 4,4 & 5 & 1,2 \\
& 16 & $\begin{array}{l}\text { Satisfação com seus hábitos alimentares } \\
\text { Satisfação com a parte variável da remuneração }\end{array}$ & 961 & 4,3 & 4 & 1,3 \\
& 17 & $\begin{array}{l}\text { Satisfação em relação à carga de trabalho que } \\
\text { tem }\end{array}$ & 961 & 4,2 & 4 & 1,5 \\
Índice global de satisfação $(\%)^{(2)}$ & 666 & 68, & 68 & 1,3 \\
\hline
\end{tabular}

(1) Ordem decrescente de satisfação média.

(2) Soma dos itens com respostas completas/valor máximo $(7 * 18)$

Por meio também da escala Likert de 1 a 7, variando de "nunca" até "sempre", construímos o segundo “Índice Global de Sensações/Atitudes”, composto por 27 indicadores, como na Tabela 3.

\section{Tabela 3 - Índice Global de Sensações/Atitudes}

\begin{tabular}{|c|c|c|c|c|c|c|}
\hline & Ordem $^{(1)}$ & Sensações e Atitudes & $\begin{array}{c}\mathrm{N} \\
\text { válido }\end{array}$ & Média & Mediana & $\begin{array}{l}\text { Desvio } \\
\text { padrão }\end{array}$ \\
\hline \multirow{3}{*}{ 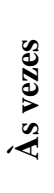 } & 1 & Ansiedade & 963 & 3,9 & 4 & 1,5 \\
\hline & 2 & $\begin{array}{l}\text { Dor de cabeça por tensão ou dor nos músculos do pescoço } \\
\text { e ombros. }\end{array}$ & 963 & 3,7 & 4 & 1,6 \\
\hline & 3 & Fadiga. & 962 & 3,6 & 4 & 1,5 \\
\hline \multirow{13}{*}{ 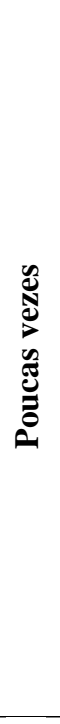 } & 4 & Dificuldade de dormir ou sono muito entrecortado. & 964 & 3,3 & 3 & 1,6 \\
\hline & 4 & $\begin{array}{l}\text { Se alimenta com frequência maior ou em maior quantidade } \\
\text { maior do que a usual. }\end{array}$ & 963 & 3,3 & 3 & 1,4 \\
\hline & 4 & Nervosismo. & 962 & 3,3 & 3 & 1,4 \\
\hline & 4 & Estresse com violência urbana. & 961 & 3,3 & 3 & 1,8 \\
\hline & 8 & Ímpetos de raiva (no trabalho, em casa, no trânsito). & 962 & 3,2 & 3 & 1,4 \\
\hline & 8 & Irritabilidade fácil. & 959 & 3,2 & 3 & 1,5 \\
\hline & 10 & Angústia & 963 & 3,1 & 3 & 1,5 \\
\hline & 11 & Diminuição do interesse sexual. & 958 & 2,9 & 3 & 1,3 \\
\hline & 11 & Sensação de desânimo pela manhã, ao levantar. & 961 & 2,9 & 2 & 1,6 \\
\hline & 11 & Medo de desemprego. & 955 & 2,9 & 2 & 1,6 \\
\hline & 14 & Indisposição gástrica ou dor de estômago. & 964 & 2,8 & 2 & 1,5 \\
\hline & 14 & Insatisfação com as relações afetivas. & 960 & 2,8 & 2 & 1,5 \\
\hline & 16 & Medo do futuro & 961 & 2,7 & 2 & 1,6 \\
\hline \multirow{4}{*}{ 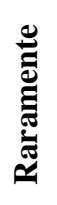 } & 17 & Sensação de fôlego curto ou de falta de ar. & 964 & 2,4 & 2 & 1,5 \\
\hline & 17 & Beber & 961 & 2,4 & 2 & 1,4 \\
\hline & 19 & Período de depressão. & 962 & 2,3 & 2 & 1,4 \\
\hline & 19 & Dores de cabeça constantes. & 960 & 2,3 & 2 & 1,5 \\
\hline
\end{tabular}




\begin{tabular}{|c|c|c|c|c|c|c|}
\hline & $\operatorname{Ordem}^{(1)}$ & Sensações e Atitudes & $\begin{array}{c}\mathbf{N} \\
\text { válido }\end{array}$ & Média & Mediana & $\begin{array}{l}\text { Desvio } \\
\text { padrão }\end{array}$ \\
\hline & 21 & $\begin{array}{l}\text { Tendência a suar em excesso ou sensação de sentir seu } \\
\text { coração batendo mais forte. }\end{array}$ & 961 & 2,2 & 2 & 1,4 \\
\hline & 22 & Redução do apetite. & 962 & 2,1 & 2 & 1,1 \\
\hline & 23 & Tremores musculares (Ex: olhos, boca, mãos). & 963 & 2,1 & 2 & 1,4 \\
\hline & 24 & Dormência pelo corpo. & 963 & 1,9 & 1 & 1,2 \\
\hline & 25 & Dor discreta no peito & 960 & 1,7 & 1 & 1,1 \\
\hline \multirow{3}{*}{$\begin{array}{l}\text { 巳 } \\
\text { 艺 }\end{array}$} & 26 & Fumar & 960 & 1,4 & 1 & 1,2 \\
\hline & 27 & Tomar pílulas para dormir & 961 & 1,3 & 1 & ,9 \\
\hline & & Índice Global de Sensações/Atitudes $(\%)^{(2)}$ & 965 & 38,3 & 37 & 11,6 \\
\hline
\end{tabular}

(1) Ordem decrescente de frequência de sensações.

(2) Soma dos itens com respostas completas/valor máximo $(7 * 27)$.

Depois, utilizamos a ferramenta ANOVA para estabelecer comparações múltiplas e verificar as diferenças mais significativas entre homens e mulheres (ver tabelas 2 e 4 ).

\section{ANÁLISE DOS RESULTADOS}

A mulher no topo da hierarquia organizacional ainda é um fenômeno raro. Nossa pesquisa corrobora a literatura: dos 965 executivos entrevistados, 222 são mulheres (23\%). Quanto mais se sobe na hierarquia empresarial, menos mulheres são encontradas: de 36 presidentes entrevistados, somente 2 eram mulheres; entre os vice-presidentes/diretores, encontramos 19\% de mulheres; no nível logo abaixo de vice-presidentes/diretores o percentual subiu para 25,1\%. O universo da alta gestão organizacional segue sendo um ambiente predominantemente masculino.

Refletindo o aumento da participação da mulher no mercado de trabalho nas décadas mais recentes, as executivas mulheres estavam concentradas nas faixas mais jovens: $40,7 \%$ das executivas mulheres têm até 30 anos e 28,2\% delas estão na faixa de 30 a 40 anos. Essas porcentagens foram estatisticamente significantes de acordo com o teste Qui Quadrado (valor $\mathrm{p}=0,000$ ).

O preconceito de que a mulher atingiu o topo da hierarquia devido ao fato de esta se comportar segundo padrões considerados masculinos ficou evidente, como exemplifica a fala de uma executiva: "Me dizem: - Você não pensa como mulher, não tem instabilidade, é bem resolvida e decidida, não traz problema pessoal para o trabalho. - Isso para mim é um elogio". Chama a atenção o fato de essa 
executiva perceber essa fala masculina como elogio, o que sugere que o preconceito está muito mais enraizado na sociedade do que se imagina, incutido não só nos homens, mas também nas próprias mulheres. Certamente, o que se entende por masculino e feminino e como esses atributos são corporificados por mulheres e/ou por homens é questão muito complexa, que precisaria de espaço muito maior do que o que dispomos aqui. Um exemplo dessa complexidade foi expresso por outras executivas entrevistadas, que enfatizaram que essa "masculinização" do comportamento feminino no ambiente de trabalho, e, portanto, essa corporificação dos atributos masculinos pelas mulheres, seria responsável pela perda de um necessário lado "diferente, feminino, de fazer a diferença" na gestão.

Encontramos também repetidos indícios do preconceito de que "determinados tipos de trabalho não são feitos para a mulher”, em especial nas indústrias investigadas, o que corrobora a literatura. Num grupo de foco conduzido numa indústria onde havia somente homens, ouvimos as seguintes frases, indicativas desse tipo de preconceito: "Fábrica não foi feita para mulher"; ou: "Achamos importante a presença da mulher. No meu setor tem duas mulheres, num grupo de mil pessoas (risos)".

A pesquisa também referendou a literatura no tocante ao favorecimento do homem executivo no contexto familiar. Sem culpa, os executivos homens, casados e com filhos, alguns com mulheres que também trabalham, diziam: "Quando estou estressado, corro na praia, jogo tênis durante umas duas horas depois do trabalho, e quando chego em casa estou relaxado", ao que as executivas respondiam: “Ah, é?! E quando você chega em casa, sua mulher já pôs os filhos para dormir? Eu não posso fazer isso, quem cuidaria das minhas crianças?" As executivas entrevistadas disseram que seus maridos, muitos deles também executivos, raramente ajudam nas tarefas com os filhos do casal. Essas tarefas não são negociadas com os maridos, as executivas preferem evitar o desgaste de uma negociação terceirizando-as para babás, motoristas, domésticas, etc. Essa dificuldade pode estar associada à geração atual de executivos mais seniores. Encontramos indícios, embora muito pequenos se comparados às respostas da maioria na pesquisa qualitativa, de que executivos homens mais novos (de 30 a 35 anos) estão mais propensos a essa renegociação.

Viagens e mudanças de moradia frequentes, demandas comuns na alta gestão, favorecem os homens, mais dispostos a deixar a família em outra cidade, e prejudicam a carreira das executivas mães, que não podem e/ou não querem se separar dos filhos. O sentimento de culpa em relação aos filhos, quase inexistente nos homens executivos entrevistados, é evidente nas mães executivas. O depoimento de uma jovem executiva ilustra bem essa situação: 
Estou em crise, pois apareceu oportunidade de ir para fora do país pela empresa. Será que vale a pena? Estou com filho pequeno, uma estrutura toda montada, agora ele já está na escolinha, meu marido tem a carreira dele... Por outro lado, sei que para crescer aqui na empresa tenho que me internacionalizar.

Não ouvimos nenhum relato sequer demonstrando qualquer relutância em mudar de cidade ou expatriar-se por parte dos 215 homens executivos entrevistados na pesquisa qualitativa.

A quantidade de executivos homens com cônjuges que não trabalham (40,5\%) é muito maior do que a das mulheres executivas cujos maridos não trabalham (7\%). Essas porcentagens foram estatisticamente significantes de acordo com o teste Qui Quadrado (valor $p=0,000$ ). Esse dado reforça o papel da mulher como "recurso fundamental de apoio" à carreira masculina. Quanto mais alto o cargo do executivo homem, menos a mulher dele trabalha fora.

De toda forma, $19,5 \%$ das executivas entrevistadas na pesquisa quantitativa já trabalham em uma cidade e residem em outra, contra $28,7 \%$ dos executivos homens. Essas porcentagens foram estatisticamente significantes de acordo com o teste Qui Quadrado (valor $\mathrm{p}=0,007$ ).

Nesse quadro, onde a mulher executiva, além da mobilidade geográfica exigida pelas empresas, tem que gerenciar sozinha as tarefas de casa e se dedicar à educação e a alguma convivência com os filhos, não é de se estranhar que o percentual de mulheres no topo da carreira que não tem filhos seja bem maior que o percentual de homens (40,5\% de mulheres contra 19,3\% de homens). Essas porcentagens foram estatisticamente significantes de acordo com o teste Qui Quadrado (valor $\mathrm{p}=$ $0,000)$.

Pelos mesmos motivos, a porcentagem de mulheres executivas de sucesso na carreira que têm apenas um filho é bem maior que a de homens (42,7\% contra 28,9\%), sendo que 54,1\% desses executivos têm dois filhos. Essas porcentagens foram estatisticamente significantes de acordo com o teste Qui Quadrado (valor $\mathrm{p}=0,013$ ). Para o homem executivo, como não é ele quem cuida, o fato de ter mais filhos não representa carga adicional de trabalho.

A pesquisa mostrou um alto grau de "terceirização" de tarefas relacionadas ao lar e aos filhos, abrangendo às vezes mais de uma babá, uma empregada e um motorista. Essa é uma das saídas encontradas pelas executivas para conciliar as demandas do trabalho com a família.

A situação fica ainda muito pior devido à extensa jornada de trabalho praticada pelos executivos brasileiros no topo da carreira. Jornadas de 12 a 14 horas diárias foram a tônica da pesquisa, além da pesada carga de trabalho, da forte tensão e de contínuas pressões. 
Nesse contexto, as mulheres executivas estão postergando a maternidade, passando a ter filhos a partir dos 30 anos. Nessa etapa da vida da mulher, a pressão do relógio biológico é crescente, fato salientado pelas executivas entrevistadas. A fala de uma executiva é representativa desse universo: "Fiz duas faculdades, MBA e mestrado, além de trabalhar muito. Quando cheguei aos 40 anos, vi uma data limite para ter ou não ter filhos. Resolvi engravidar, mas tive que fazer fertilização in vitro".

Com a maior parte do dia dedicada ao trabalho e a sobrecarga adicional para aquelas que têm filhos, a mulher executiva tem tido maior dificuldade do que seu colega homem para ou encontrar um parceiro amoroso estável e/ou manter seu relacionamento amoroso. Há quase três vezes mais mulheres executivas $(35,6 \%)$ sem parceiro amoroso estável do que homens $(13,6 \%)$. Essas porcentagens foram estatisticamente significantes de acordo com o teste Qui Quadrado (valor $p=0,000$ ).

Ficou evidente o grande incômodo para as mulheres executivas solteiras por não encontrarem parceiros amorosos estáveis, especialmente em função do relógio biológico, que de certa forma induz a mulher a encontrar um parceiro para se tornar mãe até os 35 anos de idade. $\mathrm{O}$ depoimento de uma jovem executiva solteira de 32 anos expressa esse incômodo:

Não abandonei o sonho de casar e ter filhos, porém hoje quero mais ter um filho do que me casar. As pessoas te cobram por sua situação amorosa. Sinto falta de ter alguém, mas estou numa fase em que tenho muito mais chance de me relacionar com homens separados, que muitas vezes já têm filhos. Isso é o mais complicado, pois, para o homem, essa parte de filhos já está resolvida, entretanto eu quero ter o meu.

Para as executivas casadas e com filhos, a sobrecarga de tarefas na gestão da casa e na atenção aos filhos interfere também na relação com o marido, como exemplifica o desabafo de uma executiva, que reflete a indisponibilidade psicológica discutida no referencial teórico: "Muitas vezes chego em casa e a única coisa que eu quero é tomar um banho e ir para a cama, mas as demandas são inúmeras, lições de casa, afeto, atenção... ainda tem meu marido. Me sinto totalmente sem energia para as suprir". As executivas com filhos pequenos se sacrificam ainda mais, realizando algumas tarefas de madrugada, de 5:30 às 7:30, "Enquanto meu marido ainda está dormindo, para não comprometer nossa relação".

Outras executivas casadas, mesmo sendo as maiores provedoras do lar (ganham mais que seus maridos), ainda submetem o orçamento a estes, escondendo ou ouvindo reprimendas de seus parceiros amorosos por terem comprado vestidos e outros mimos femininos (com o dinheiro ganho por elas).

A canção de Ataulfo Alves denominada “Amélia” (letra de Mário Lago, 1941) descreve a mulher "ideal", submissa ao homem, que se desdobrava para lhe agradar (e ainda por cima foi trocada 
por outra). A mulher executiva continua se desdobrando, e tem sofrido com a sobrecarga imposta por ela mesma e por seus diversos papéis de mulher, mãe e profissional. Muitas vezes ainda se submete ao homem, se sobrecarregando com o cuidado rotineiro da casa e dos filhos, se cobrando por estar bonita, magra, fazendo atividade física, com a pele, as unhas e os cabelos bem cuidados, e por ter sucesso profissional, e, ainda por cima, tomando cuidado para não ofuscar o sucesso do seu par amoroso.

Por todas essas razões, as mulheres seguem mais sozinhas $(35,6 \%)$ que os homens executivos $(13,6 \%)$, sem um parceiro amoroso constante. Essas porcentagens foram estatisticamente significantes de acordo com o teste Qui Quadrado (valor $\mathrm{p}=0,026$ ). A grande maioria das executivas disseram, na pesquisa qualitativa, que o fato de estarem mais sozinhas as incomoda. O número de executivas mulheres sem parceiro amoroso constante é ainda maior no nível da gerência de terceiro escalão do que na vice-presidência e diretorias (segundo escalão, logo abaixo do presidente). Uma explicação relaciona-se com a faixa etária das executivas do terceiro escalão, mais jovens do que as mulheres nas vice-presidências e diretorias, o que corrobora a dificuldade das executivas mais jovens em achar parceiro amoroso que corresponda ao timing do relógio biológico delas, problema exacerbado pela falta de tempo de todas as executivas para cultivar uma relação amorosa.

A tônica geral do discurso foi de jovens executivas dando conta da dificuldade até mesmo de iniciar uma relação amorosa que não fosse dentro da própria empresa onde elas trabalham, por absoluta falta de tempo, já que a jornada de trabalho é excessivamente longa.

$\mathrm{O}$ tratamento dos dados mostrou que as mulheres executivas estão menos satisfeitas no geral que os homens, como indicam as Tabelas 2 e 4 em seguida. A insatisfação maior, tanto das mulheres quanto dos homens, deu-se quanto à relação com chefes, pares e subordinados, bem como em relação ao sistema de compensação. No entanto, em todos esses quatro fatores, as mulheres executivas estão ainda mais insatisfeitas do que os homens executivos.

Tabela 2 - Índice Global de Satisfação Médio, mulheres e homens executivas(os)

\begin{tabular}{lc}
\hline \hline Sexo & Índice Global de Satisfação Médio (\%)* \\
\hline \hline Feminino & $65,46 \downarrow$ \\
Masculino & $68,49 \uparrow$ \\
\hline \hline
\end{tabular}

* ANOVA: Comparações múltiplas com valor $\mathrm{p} \leq 0,05$. 
Tabela 4 - Índice Global de Sensações e Atitudes Médio, mulheres e homens executivas(os)

\begin{tabular}{cc}
\hline \hline Sexo & Índice de Sensações/Atitudes Médio* \\
\hline \hline Feminino & $41,13 \uparrow$ \\
Masculino & $37,50 \downarrow$ \\
\hline \hline
\end{tabular}

* ANOVA: Comparações múltiplas com valor $\mathrm{p} \leq 0,05$.

Já quanto ao Índice Global de Sensações e Atitudes, também nesse caso a frequência dos fatores relacionados aos sintomas de estresse foi mais alta entre as mulheres (ver tabelas 3 e 4). As mulheres são as que mais frequentemente têm sintomas emocionais, dores de cabeça/indisposição, problemas com as relações afetivas e mudanças na alimentação. As relações afetivas são mais percebidas pelas mulheres como insatisfatórias ou não tão satisfatórias, enquanto para os homens isso não se traduz em incômodo expresso.

Apesar de todos os pesares, as executivas que conseguiram alcançar o topo da carreira gostam do que fazem e, no geral, não abandonariam a carreira para se dedicarem mais à família. O desejo masculino machista, popularizado no samba que enaltece os predicados das "Amélias", que seriam mulheres "de verdade" porque se dedicariam inteiramente aos homens, está muito distante de se concretizar, a depender do sentimento das executivas que estão na direção das grandes empresas. $\mathrm{O}$ desabafo de uma executiva que se questionou muito em relação à sua satisfação com a carreira e à dedicação à família, embora reforce o conflito de papéis vivenciado e discutido acima, é emblemático no sentido de que, apesar de todos os desafios, não vale a pena abandonar a arena: "Já questionei muito se deveria priorizar tanto a vida profissional. Resolvi parar de trabalhar e não deu certo. Não tenho perfil de 'Amélia'. Essa decisão de largar tudo foi uma ilusão".

\section{CONSIDERAÇÕES FINAIS}

Num ambiente predominantemente masculino, as mulheres executivas têm que lidar com uma carga considerável de preconceitos machistas por parte de superiores, pares e subordinados, vivenciando a contradição apontada na literatura (BETIOL; TONELLI, 1991; BELLE, 1993; AYCAN, 2004; REINHOLD, 2005) de trabalhar "como homem" versus ser "feminina". Nossa pesquisa mostrou que isso incomoda grande parte das executivas. 
Por outro lado, chamou a atenção como algumas executivas sequer percebem o preconceito como tal, assumindo-o como elogio (do tipo: "Você não tem essas coisas de mulher, como instabilidade emocional"). Os estereótipos machistas estão tão arraigados culturalmente que por vezes não são percebidos por suas próprias vítimas. A pesquisa mostrou casos de executivas que, apesar de terem se tornado as maiores provedoras de seus lares, ainda se submetiam aos maridos como se eles tivessem o direito de definir o orçamento familiar. Estender uma jornada de trabalho já bastante longa, acordando mais cedo, antes do marido, para realizar tarefas que ele poderia compartilhar e não o faz, foi também outro resquício de puro machismo encontrado e ainda aceito pela maioria das mulheres executivas.

O sentimento de culpa das mulheres executivas em relação aos filhos, devido a incontornáveis ausências, ficou evidente. A pressão exercida sobre elas pelas suas próprias mães aumenta ainda mais a culpa. Esse é mais um indicador dos estereótipos machistas arraigados culturalmente nas próprias mulheres (BOURDIEU, 1999), que, por sua vez, são importantes transmissoras desses valores por meio da educação dos filhos.

No contexto familiar, a mulher executiva ainda é praticamente a única responsável pela gestão da casa, das tarefas e cuidados relativos aos filhos, incluída nessa gestão a logística (babás e motoristas) que pressupõe a agenda das crianças. Esses achados corroboram a literatura (HEWLETT, 2002).

Nos grupos de foco, onde se encontravam homens e mulheres executivos(as), foram constantes os embates produzidos pela indignada reação feminina à absoluta falta de sensibilidade masculina em relação às tarefas domésticas e ao cuidado com os filhos.

Mas não é somente na seara dos preconceitos em relação à mulher que a executiva enfrenta significativos desafios. A dimensão estrutural do mundo do trabalho do executivo em topo de carreira traz desafios consideráveis para todos, porém a pressão é muito mais forte sobre elas. A pesquisa mostrou que o ambiente das grandes empresas, extremamente competitivo e mutante, exige cada vez maior dedicação à carreira, além de mobilidade geográfica e flexibilidade de horários. Essas demandas desfavorecem sobremaneira as mulheres executivas casadas, especialmente com filhos pequenos, o que corrobora a literatura (NEUMARK; MCLENNAN, 1994; KIRCHMEYER, 1998; REINHOLD, 2005). As poucas tentativas detectadas entre as mulheres de desistir da carreira foram frustrantes.

A maioria das mulheres que alcançaram o nível que corresponde ao terceiro escalão é mais jovem (31 a 40 anos). Nessa faixa de idade, a pressão do relógio biológico é grande para a mulher que quer filhos, o que aguça o conflito de papéis no trabalho e na família. Como indicou esta pesquisa, além de dados de pesquisas anteriores (VIRTALA e outros, 2006), postergar o momento de ter filhos 
tem sido uma estratégia, mas é uma fonte de sofrimento. Tentar ter filhos depois e não conseguir, ou ter dificuldades para engravidar, tem impacto forte na felicidade da mulher, pois os tratamentos são dolorosos e trazem sofrimento psicológico.

Outra necessidade fundamental da vida humana, o relacionamento amoroso, também é fonte de insatisfação maior para a mulher executiva do que para o homem. A pesquisa, tanto na parte qualitativa quanto na parte quantitativa, evidenciou que é mais difícil para a mulher encontrar um parceiro amoroso. Quanto mais alto o cargo da mulher, mais difícil é para ela encontrar um parceiro amoroso, pois, conforme lembra Freitas (1998), o homem lida mal com as ausências devido ao trabalho, e se sente ameaçado e inseguro com o sucesso profissional da mulher. Por outro lado, quanto mais alto o cargo do homem, menos a mulher dele trabalha fora.

Num quadro desses, não é de se estranhar que as mulheres executivas estejam mais estressadas e mais insatisfeitas com a falta de equilíbrio entre a vida pessoal e a profissional do que os homens, o que também corrobora a literatura (BETIOL E TONELLI, 1991).

Mesmo com esse colossal conjunto de desafios à carreira, a mulher conseguiu chegar ao topo da hierarquia organizacional das maiores empresas no Brasil, país onde os valores machistas são especialmente dominantes. Apesar de todos os pesares, a grande maioria das mulheres que atingiram o Olimpo empresarial continua apostando na carreira, tendo prazer e se realizando no trabalho.

$\mathrm{O}$ fato de as mulheres executivas expressarem sua insatisfação não significa uma negação da carreira, e sim um primeiro passo na busca de um necessário equilíbrio entre seus tempos de trabalho e de não trabalho. Elas estão pagando um alto preço para ascender na carreira executiva com o mínimo de equilíbrio nas outras esferas de sua vida, mas não fogem da luta. Esse desejo de não retornar à posição anterior, de dominação masculina - que é, conforme salienta Bourdieu (1999), aquilo que opera por um processo de naturalização que transforma o arbitrário cultural em fato natural - força que as pessoas e as empresas repensem seus papéis e suas práticas.

Certamente, não dá para esperar que uma mudança significativa venha dos homens, que estão numa posição mais confortável. Cabem ações afirmativas para minimizar essas dificuldades por parte da direção das empresas, das quais fazem parte, ainda que em minoria, as próprias executivas, que têm um papel central nesse desejável movimento. Na seara familiar, a renegociação dos papéis, especialmente das tarefas domésticas, não é fácil, mas deve ser empreendida pelas mulheres.

O que este artigo traz de novo é a percepção dessa nova mulher, que conquistou um lugar disputado pelos homens, combatendo e sofrendo vários preconceitos, e quer um melhor equilíbrio entre 
vida pessoal e carreira, e, principalmente, não quer voltar atrás, não quer abandonar seu lugar no topo da gestão nas grandes empresas brasileiras.

Uma perspectiva de aprofundamento teórico que nosso estudo levanta é - a partir de Guiddens (2003), que trabalha o conceito de consequências imprevistas a partir do construto de consequências impremeditadas cunhado originalmente por Merton (1968) - sobre essa mulher que chegou ao centro do poder econômico pela primeira vez no capitalismo nessa proporção, e certamente não aceita mais a dominação masculina. As consequências imprevistas desse movimento de ascensão da mulher justificam novos estudos. Nosso estudo levanta também a possibilidade de avanço no conhecimento de novas perspectivas relacionadas às conquistas do feminismo de um ponto de vista de uma mulher que luta pelo poder nas empresas, que não quer voltar atrás, que sofre com o impacto em sua vida pessoal e ainda não sabe muito bem como conciliar seus diversos papéis.

\section{Nota}

* Agradecemos à Fundação de Amparo à Pesquisa do Estado de Minas Gerais (FAPEMIG) pelo apoio ao NERHURT- Núcleo de Estudos em Recursos Humanos e Relações de Trabalho - PPGA da PUC Minas, cuja pesquisa deu origem a este artigo.

\section{REFERÊNCIAS}

AYCAN, Z. Key success factors for women in management in Turkey. Applied Psychology: An International Review, v. 53, n. 3, p. 453-477, 2004.

BELLE, F. Executivas: quais as diferenças na diferença. In: CHANLAT, J. F. O indivíduo nas organizações. São Paulo: Atlas, 1993.

BOURDIEU, P. A dominação masculina. Rio de Janeiro: Bertrand Brasil, 1999.

BETIOL, M. I. S; TONELLI, M. J. As mulheres executivas e suas relações de trabalho. RAE-revista de administração de empresas, v. 31, n. 4, p. 17-33, 1991.

BRUSCHINI, C. Gênero e trabalho no Brasil: novas conquistas ou persistência da discriminação? In: ROCHA, M. I. B. (Org) Trabalho e gênero: mudanças, permanências e desafios. Campinas: ABEP, NEPO/Unicamp e Cadeplar/UFMG; São Paulo: 34, 2000. 384 p. 
CAPPELLE, M. C. A. O trabalho feminino no policiamento operacional: subjetividade, relações de poder e gênero na oitava região da PMMG. Tese de doutorado em Administração, Cepead/UFMG, Belo Horizonte, 2006.

CHÊNEVERT, D; TREMBLAY, M. Managerial career success in Canadian organizations: is gender a determinant? Journal of Human Resource Management, v. 13, n. 6, p. 920-941, 2002.

CHINCHILlA, M. N; LEÓN, C. Female Ambition: How to reconcile work and family. New York: Palgrave Macmillian, 2005.

CHURCHILL, G. A. Basic marketing research. 2. Ed. Fort Worth: Dryden Press, 1992.

CRESWELL, J. W. Research Design: qualitative, quantitative and mixed method approaches. London: Sage, 2003.

EVANS, P; Bartolomé, F. Must success cost so much? London: Grant McIntyre, 1980.

FISCHLMAYR, I. C. Female self-perception as barrier to international careers. Journal of Human Resource Management, v. 13, n. 5, p. 773-783, 2002.

FREITAS, M. E. Contexto social: o mundo do trabalho, a família e os "eternos" adolescentes. RAE Light, v. 5, n. 2, p. 2-6, 1998.

GIL, A. C. Métodos e técnicas de pesquisa social. 5 Ed. São Paulo: Altas, 1999.

GLANZ, L; WILLIAMS, R; HOEKSEMA, L. Sensemaking in expatriation - a theoretical basis. Thunderbird International Business Review, v. 43, n. 1, p. 101-119, 2001

GRYBAITÉ, V. Analysis of theoretical approaches to gender pay gap. Journal of Business Economics and Management, v. 7, n. 2, p. 85-91, 2006. 
GUIDDENS, A. A constituição da sociedade. São Paulo: Martins Fontes, 2003.

HEWLETT, S. A. Creating a life: professional women and the quest for children. New York: Hyperion, 2002.

HOFSTEDE, G. Cultures consequences: comparing value, behaviour, institutions and organizations across nations. California: Sage, 2001.

KIRCHMEYER, C. Determinants of managerial career success: evidence and explanation of male/female differences. Journal of Management, v. 24, n. 6, p. 673-692, 1998.

MARTINS, L. L; EDDLESTON, K. A; VEIGA, J. F. Moderators of the relationship between workfamily conflict and career satisfaction. Academy of Management Journal, v. 45, n. 2, 399-409, 2002.

MERTON, R. Social Theory and Social Structure. New York: The Free Press, 1968.

MINGOTI, S. A., Análise de dados através de métodos de estatística multivariada: uma abordagem aplicada. Belo Horizonte: Editora UFMG, 2005.

NEUMARK, D; MCLENNAN, M. Sex discrimination and women's labor market outcomes. The Journal of Human Resources, v. 30, n. 4, p. 713-40, 1994.

QUENTAL, C; WETZEL, U. Equilíbrio trabalho-vida e empreendedorismo: a experiência das mulheres brasileiras. In: ENCONTRO NACIONAL DA ASSOCIAÇÃO DOS PROGRAMAS DE PÓS-GRADUAÇÃO EM ADMINISTRAÇÃO, 26, 2002, Salvador. Anais. Salvador/: ANPAD, 2002.

REINHOLD, B. Smashing glass ceilings: why women still find it tough to advance to the executive suite. Journal of Organizational Excellence, v. 24, n. 3, p. 43-55, 2005.

TANURE, B. Gestão à brasileira: somos ou não diferentes? - Uma comparação com América Latina, Estados Unidos, Europa e Ásia. 2. Ed. São Paulo: Atlas, 2005. 
TAYLOR, S; NAPIER, N; MAYRHOFER, W. Women in global business: introduction. International Journal of Human Resource Management, v. 13, n. 5, p. 739-742, 2002.

TONELLI, M. J. Feitos para não durar: emprego e casamento no final do século. In: ENCONTRO NACIONAL DA ASSOCIAÇÃO DOS PROGRAMAS DE PÓS-GRADUAÇÃO EM ADMINISTRAÇÃO, 27, 2000, Florianópolis. Anais. Florianópolis: ANPAD, 2000.

TRIOLA, M. F. Introdução à estatística. 7. Ed. Rio de Janeiro: LTC, 1999.

VAN VIANEN, A; FISHER, A. Illuminating the glass ceiling: the role of organizational culture preferences. Journal of Occupational and Organizational Psychology, v. 75, n. 3, p. 315-337, 2002.

VIRTALA, A; KUNTTU, K; HUTTUNEN, T; VIRJO, I. Childbearing and the desire to have children among university students in Finland. Acta Obstet Gynecol Scand., v. 85, n. 3, p. 312-316, 2006.

WAJNMAN, S; RIOS-NETO, E. L. G. Quantas serão as mulheres: cenários para a atividade feminina. In: ROCHA, M. I. B. (Org) Trabalho e gênero: mudanças, permanências e desafios. Campinas: ABEP, NEPO/Unicamp e Cadeplar/UFMG; São Paulo: 34, 2000. 384 p.

WERKEMA, M. C. C; DRUMOND, F. B; AGUIAR, S. Análise de variância: comparação de várias situações. Belo Horizonte: Fundação Cristiano Otoni, Escola de Engenharia/UFMG, 1996. 